\title{
تشتت الإنتباه وفرط الحركة لدى الأطفال
}

\author{
(إعراد \\ الباحثة/ شرين محمد عطا محمد \\ باحثة ماجستير

$$
\text { إشر افـ }
$$ \\ أ.د/ حسيز محمد سعد الدين الحسيني \\ أستاذ علم النفس \\ بكليت الآداب - جامعت المنصورة
}

المجلت العلميت لكليت التربيت للطفولت المبكرة ـ جامعت المنصورة

$$
\begin{aligned}
& \text { المجلد السابع ـ العدد الثانى } \\
& \text { أكتوبر r.r. }
\end{aligned}
$$




\section{تشتت الإنتباه وفرط الحركة}

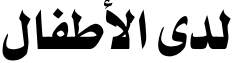

* شربن محمد عطا محمد

يعد الإنتباه أحد العمليات العقلية التي تلعب دور اً مهماً في حياة الفرد مــن

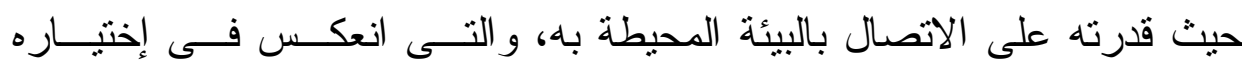
للمنبهات المختلفة و المناسبة، كتى يتمكن من دقة تحليليها و إدر اكها، و الإســتجابة لها بصورة تجعله يتكيف مع بيئته الاخليةً أو الخارجية.

وقد حظى الإنتباه باهتمام كثير من الباحثين على إعتبار أنه العملية التـى

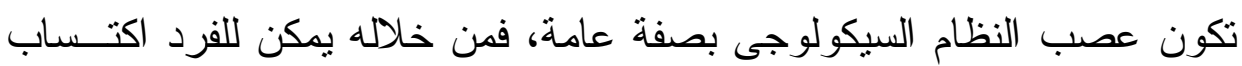
الكثير من المهار ات، وتكوين كثير مــن العــادات الـسلوكية المتعلمــة التـى فئى

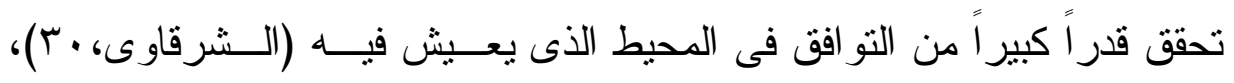

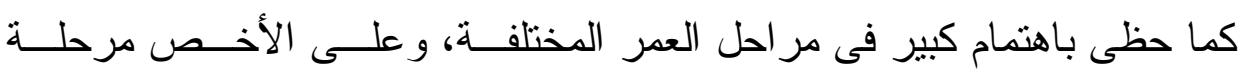
الطفولة.

ونظر اً لأن الإنتباه عملية عقلية نمائية، فإنه يلاحظ على الأطفــال عــدم

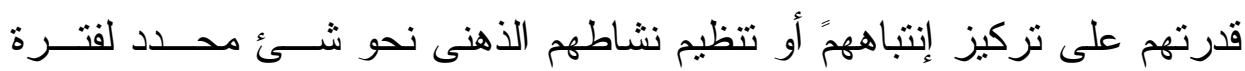

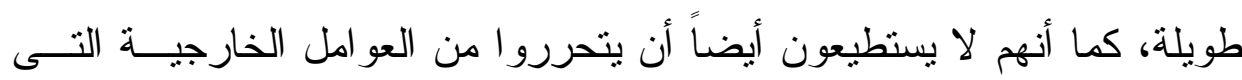

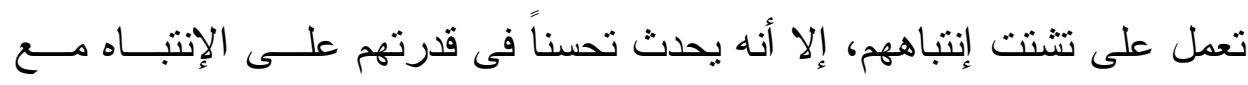

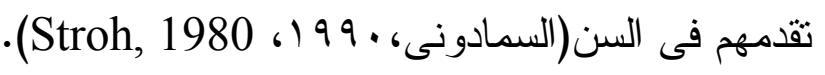

* باحثتة ماجستير * المجلد السابع




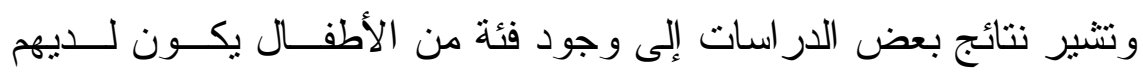

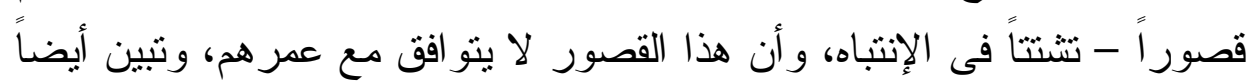

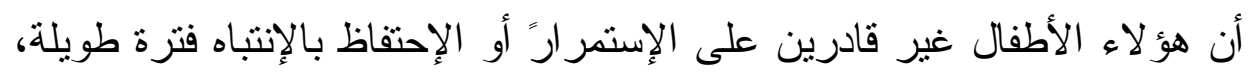

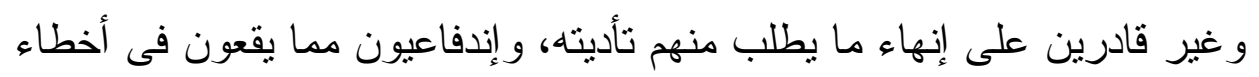

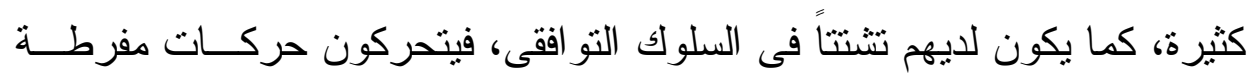

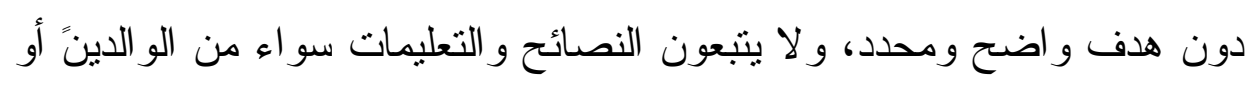

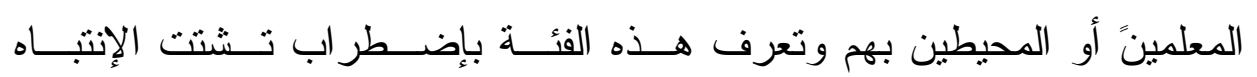

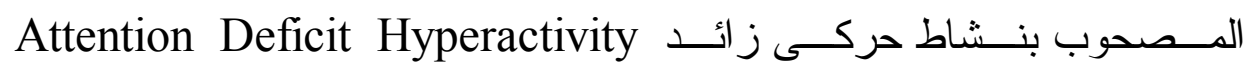

.(ADHD)Disorder

(Apa, 1987, Barkely, 1990, Brit o, et al, 1995, Carlson, et al, 1995, Dykman, et al, 1981, Lanowski, 1985)

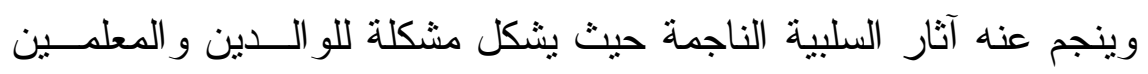

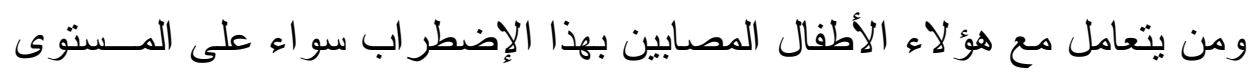

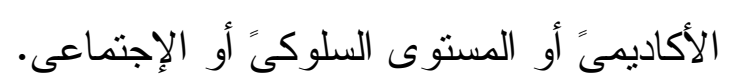

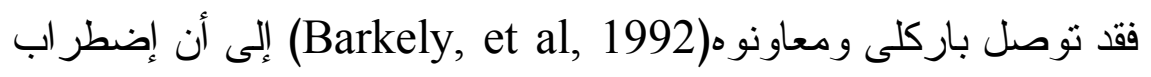

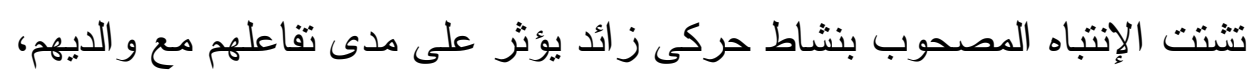

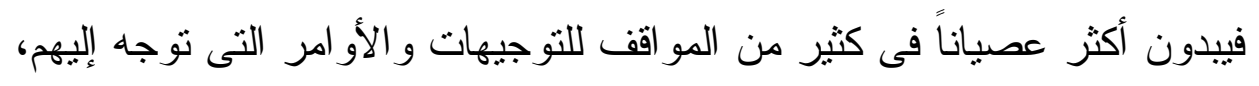

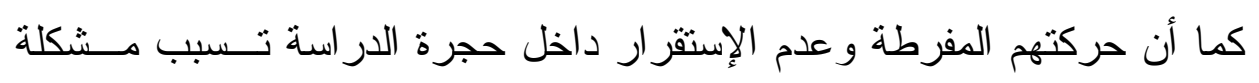
للمعلم، وللطفل ذاته.

وقد أنشار جيبسون (Gibson, 1978) أن الأطفال مــضطربى الإنتبـــاه

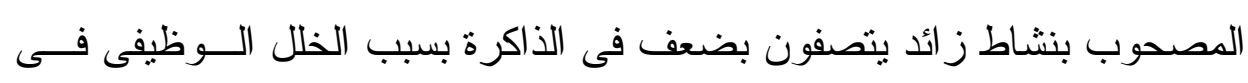

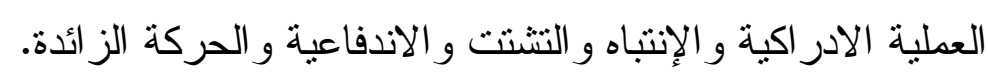

r.r.r. العدد الثانى : أكتوبر 
(Gordon, EtAl, 1991, Kendall, 1990, Dupaul, 1971, Kaiser, 1993, Michanbaum \&Goodman, 1971, Douglas, et al, 1976, Gurney, 1987, Leung, et al, 1991)

إن إضطر اب نتشت الإنتباه المصحوب بنشاط حركى زائد يــؤدى إلـى ظهور مشكلات الأطفال منها صعوبة اكتساب الخبرات للمهــار ات الأساسـية،

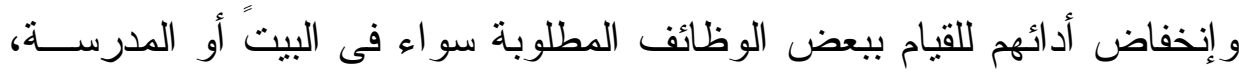

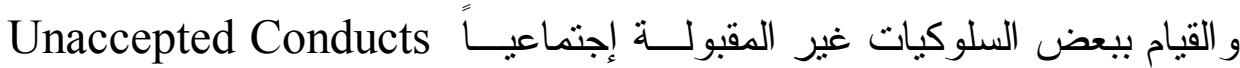
.Behaviors

ونظر اً لأهمية الإنتباه و التركيز وما يحدث بهما مــن إضــــر ابات لهــا

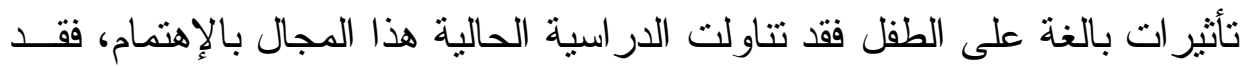

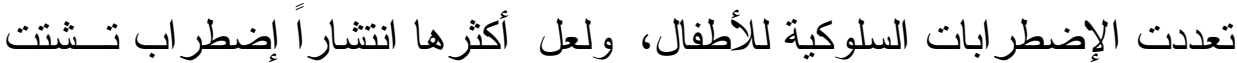
الإنتباه المصحوب بالنشاط الز ائد، وبغية التعرف على هذا الاضطر اب أكثر تـم

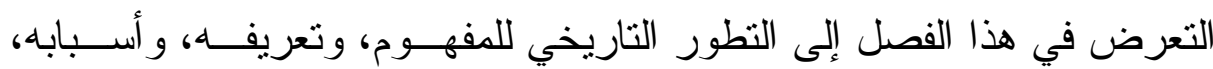
و أعر اضه وطرق تثخيصه، وطرق علاجه.

\section{التطور التاريخى لإضطر اب تشتت الإنتباه المصحوب بالنشاط الزائد}

أخذت مشكلة إضطر اب تشنت الإنتباه المصحوب بالنـشاط الزائـــــــى

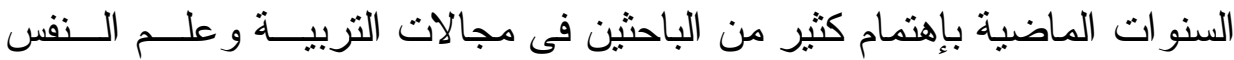

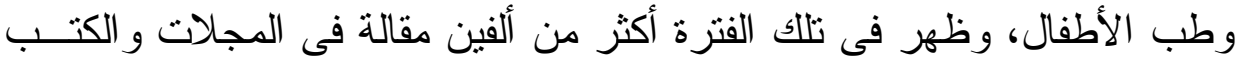
العلمية المتخصصة، وتتاولوها من زو ايا متعددة.

وخلال تلاك الفترة ظهرت أوصاف ومسميات متعددة لإضطر اب الإنتبـــاه

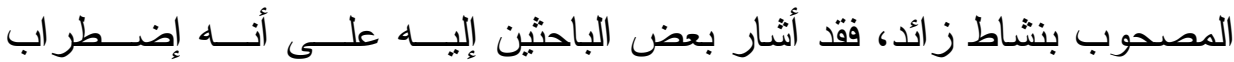

r.r. المجلد السابع


،ضوى، بينما رآى البعض الآخر أنه إضطر اب سـلـوكى(الـسمادونى،9199،

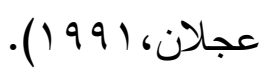

وبمر اجعة مجموعة من الدر اسات و البحوث التى اهتمت بالإضــطر ابات

السلوكية فى مرحلة الطفولة، تبين إلى أن در اسة تلك الإضطر ابات قد بدأت فى بـ

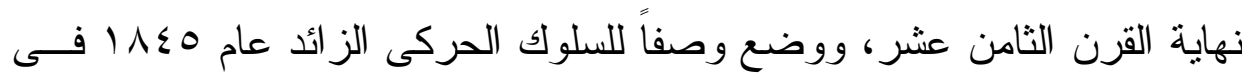

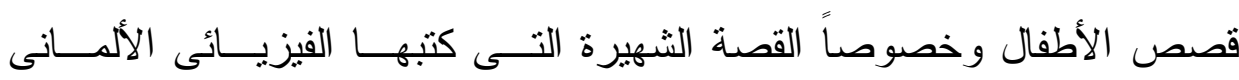
هيريتش هوفمان Heirich Hoffman و المعـروف باســ Unkempt peter.

(Meghadam\&Fagan, 1994:13)

ونتيجة إصابة الكثير من الثعوب فى نهاية الحرب العالميــة بإصــابات

دماغية بسبب إنتشار وباء التهاب المخ، تبين أن الأطفال المــصابين بتخلـــ أو

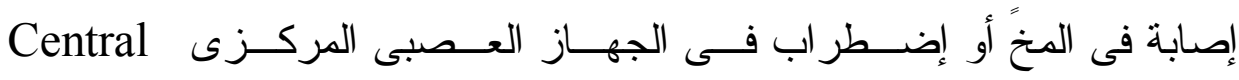
Nervous System

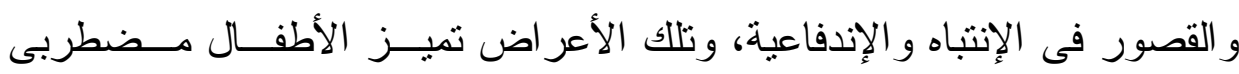
الإنتباه المصحوب بالنشاط الز ائد(Jones, 1991).

وفى العقود الأولى من القرن العشرين إهتم الباحثون بدر اســـة مـستويات

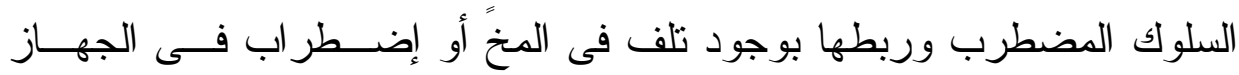
العصبى المركزى (Paul, 1985:73)، و أكــدت در اســـة ســنز اوس وليتـنـن (strauss\&lehtinen, 1947) و وإضطر اب الإنتباه يحدثان نتيجة خلل وظيفى بالمخ) Minimal Brain (MBD) Dysfunction

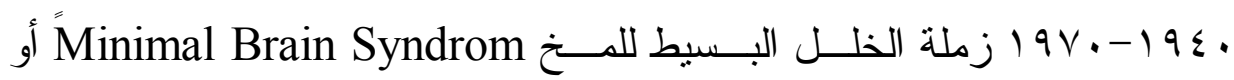


Hyperkinetic الخلل الوظيفى البسيط للمخ وأيضاً رد الفعل الحركى المفـرط .Reaction

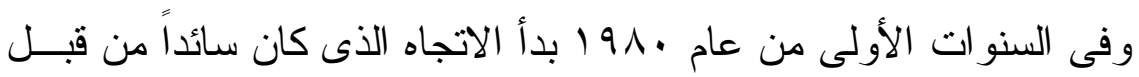

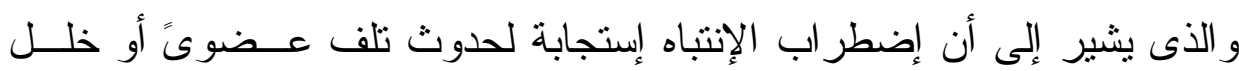

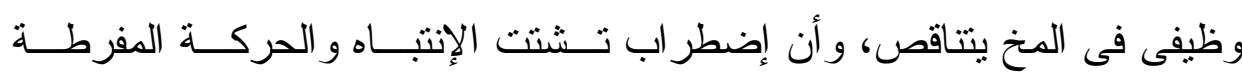

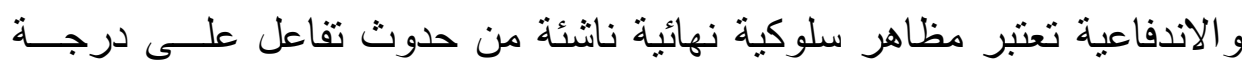
عالية من التعقيد بين خصائص الفرد) (Deuel, 1981). وبذلك بدأ ينظر إلى إضطر اب تشتت الإنتباه المصحوب بنشاط زائد لاى

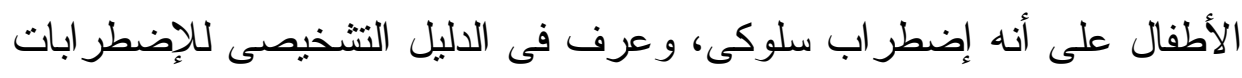

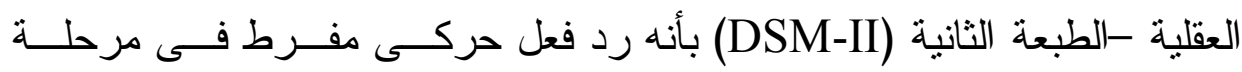

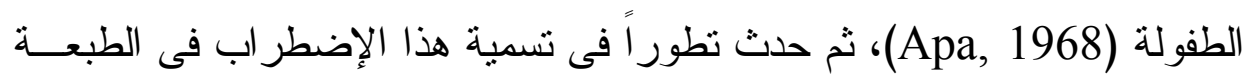

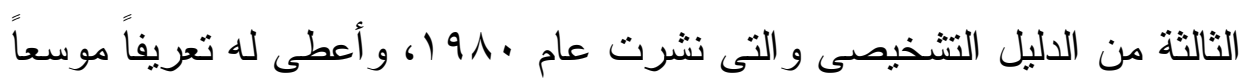

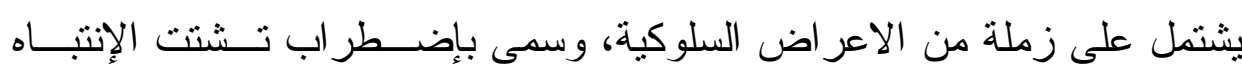
.Attention Deficiet Disorder وقد صنف هذا الإضطر اب فى فئتين فرعيتين، تعرف الأولى بإضطر اب الماب

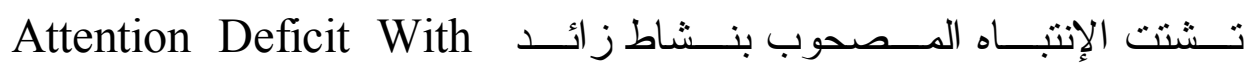
( Add-W ) Hyperactivit

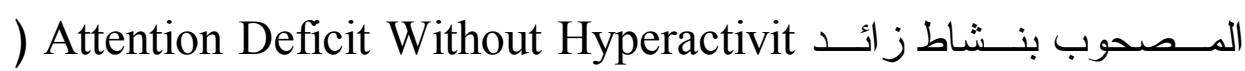
.(Apa, 1968) ( Add-Wh

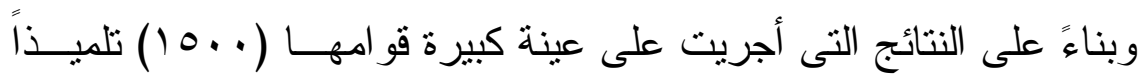

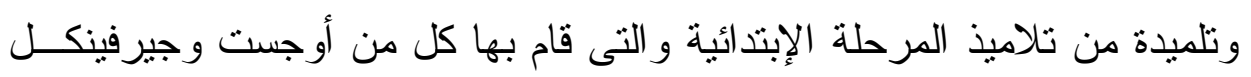


و والتى تثتير إلى أنه يوجد تأييد بسيط جداً لفئــة

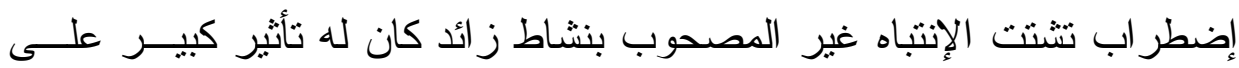

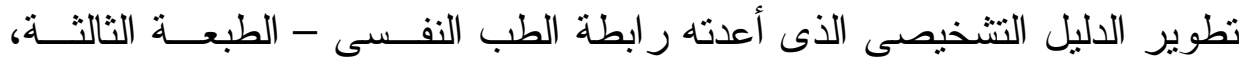

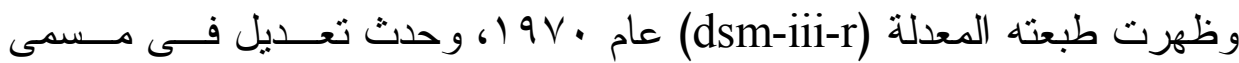
إضطر اب الإنتباه إلى مسمى إضطر اب تنتت الإنتباه المصحوب بنثاط حركى

إن مصطلح إضطر اب تشتت الإنتباه المصحوب بنشاط حركى زائد جــاء نتيجة التداخل بين المصطلح الذى عرف فى الطبعة الثانية من الدليل التتخيصى

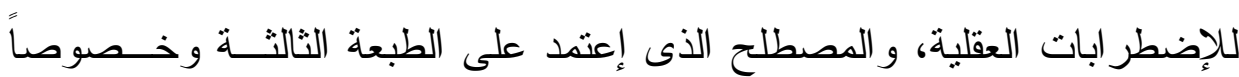
إضطر اب تشتت الإنتباه المصحوب بنشاط زائد.

وقد أثنار نيوكونومعاونوه (Newcorn, et al, 1989) أن فئة إضطر اب

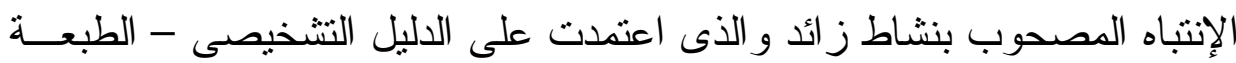

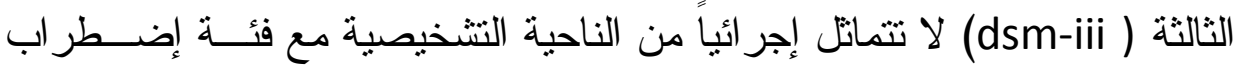

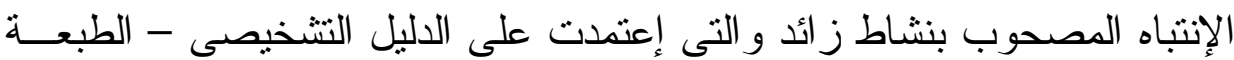

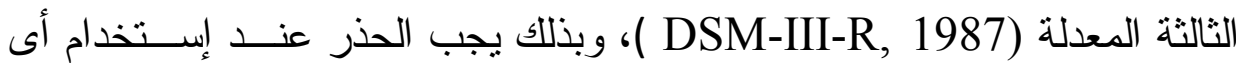

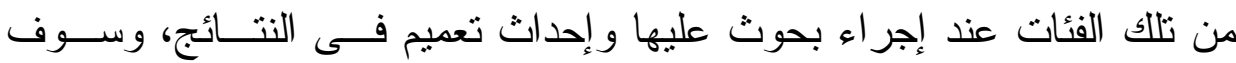

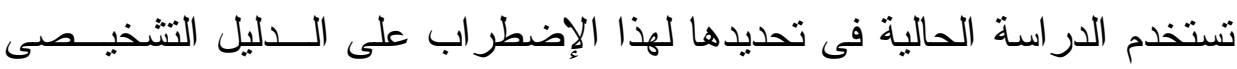
الطبعة الر ابعة) DSM-iV, 1994).

\section{تعريف إضطر اب تثتت الإتباه المصحوب بالنشاط الزائد}

تعددت تعاريف إضطر اب النشاط الز ائد المصحوب بتتشت الإنتباه تبعــاً

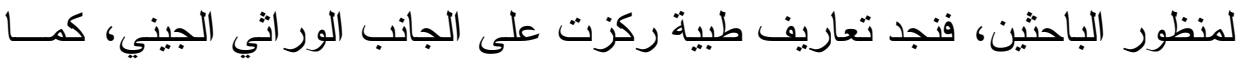

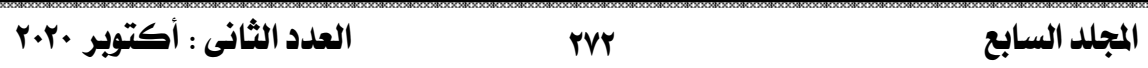


نجد من عرف الإضطر اب تبعاً للجانب السلوكي الملاحظ، خاصة منها الحركات الجسمية وتشتت الإنتباه، إلا أن التعاريف تتكامل مع بعـــها الــبعض وســيتت عرضها فيما يلى: - nئى

ورد فى الاليل النشخيصى الإحصائى للإضطر ابات العقلية أن إضطر اب تتشت الإنتباه Attention Deficiet Disorder يعنى عدم القدرة على الإنتبـــاه

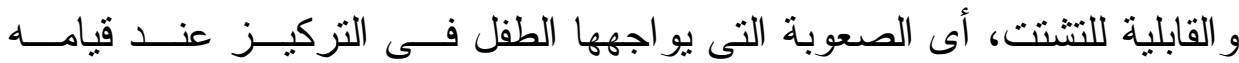
بالنشاط ويكون نتيجته عدم القدرة على إكمال النشاط بنجاح. وقد وضعت ر ابطة الطب النفسى الأمريكى(Apa, 1980) وصفاً للطفـلـ

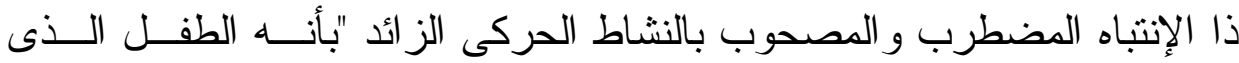
يتصف بالتتنتعن الإنتباه و المتمثل فى الصعوبة فى التزكيز ، و عدم القدرة علـى إنهاء الأعمال التى توكل إليه إضافة إلى ذلك الحركة المفرطة دون هدف محدد. وفى الغالب يلاحظ على هؤلاء الأطفال أنهم لا يصنون جيداً لمــا يقــال لهم، كما يتسمون بعدم الدقة فى أدائهم على أى نشاط يتناسب مع سنهم(p, 40). كما وضع كل من فر انـلك ومعــاونوه (Frank, et al., 1989) وو الــن (Whalen, 1989:147) المصحوب بالنشاط الحركى الزائد " بأنه الأطفل الذى يتــصفون عـــادة بإنتبـــاه

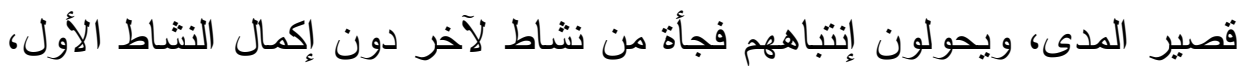
أى أنهم غير قادرين على ضبط إنتباههم وتوجيهه بصورة مرضية، ويظهـرون

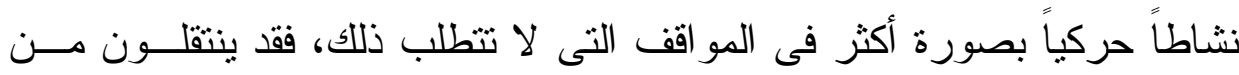
مكان لآخر بصورة مز عجة ومستمرة، وفى داخل حجرة الدر اســة، ويخرجــون

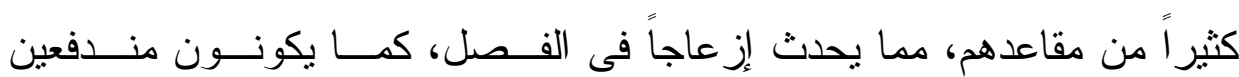
ومتهورين ويقاطعون الآخرين أثناء الحديث، ولا يصغون جيداً للحديث. 
وقد وضع جولد ستين وجولدسـتين (Goldstin, Goldstin, 1990:8) تعريفاً لإضطر اب تشتت الإنتباه المصحوب بنشاط حركى زائد إعتمد على نتائج

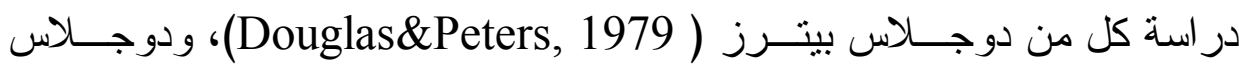

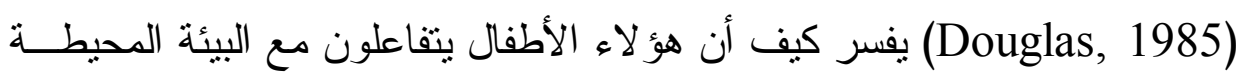

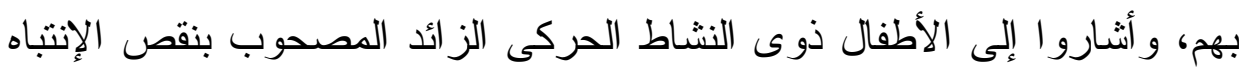

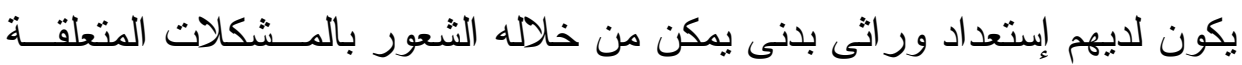

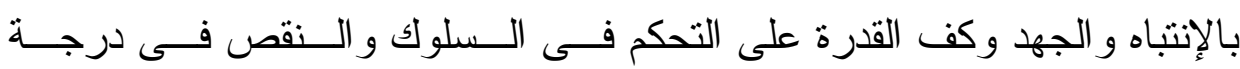
الاستتارة و الحساسية لها، ويشتمل هذا الوصف على المكونات الأربعة التالية:-

$$
\text { 1. القدم القدرة على الإتتباه }
$$

لقد عرف منذ فترة طويلة أن الأطفال من ذوى إضطر اب تشتت الإتنبـــاه

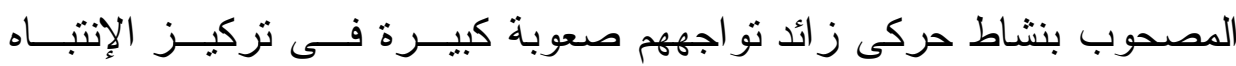

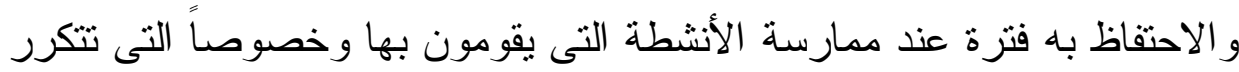

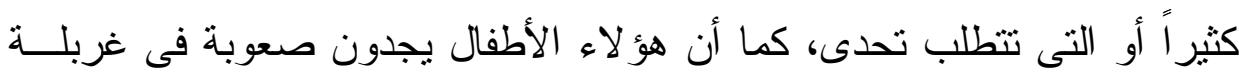

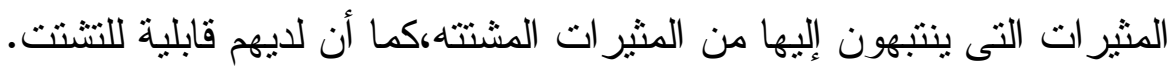

(Distractanility Strauss\&Kephart, 1955) Yver Arousal النشاط الحركى الزائد (الاستثارة الزائدة) يتميز الأطفال من ذوى إضطر اب تشتت الإنتباه المصحوب بنشاط حركى إنى

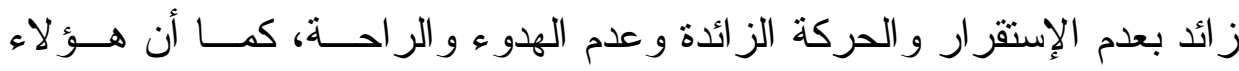
الأطفال من السهل إستثارتهم انفعالياً.

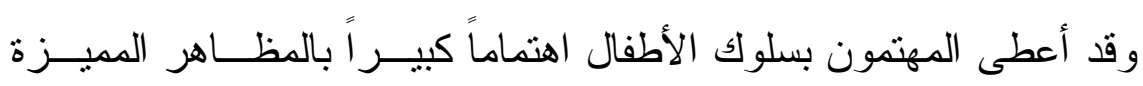

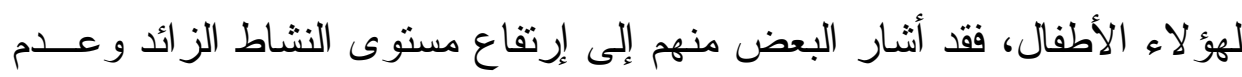

r.r. r TrE

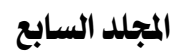


التقبل الاجتماعى لحركاتهم المفرطة. فقد يقومون بحركات عصبية مربكة وغير

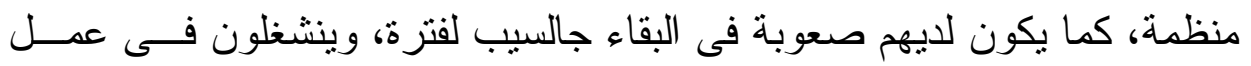

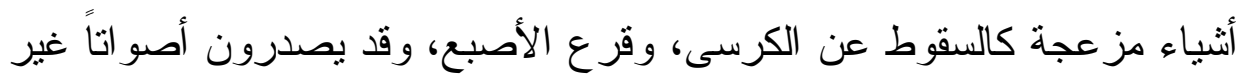
ملائمة محدثين ضوضاءً أو يتكلمون بصوت عزبه عالى (fowler, 1991:1). كما أثنار باركلي Barkaly (990 1) أن تلاك المظاهر تكون نفس الصفات التى وصفها المعلمون، و التى يصفها الأطفال ذوى النشاط الحركى الز ائد داخـلـل

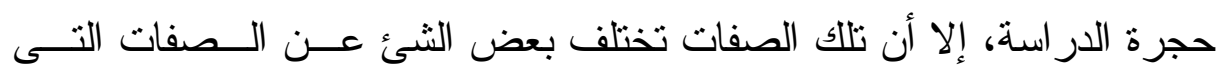
يتصف بها المر اهقون من تلك الفئة(p.3). (Peters\&Davies, 1981)

\section{Impulsivity الإخدفاعية}

أن الأطفال من ذوى إضطر اب تشتت الإنتباه المصحوب بنشاط حركى

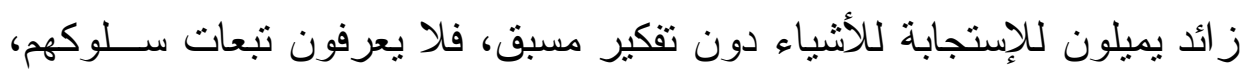

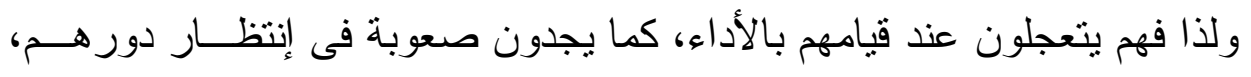
و لا يفكرون فى البدائل المطروقة قبل أن يضعون قرارهم ( Goldstein, et al,

وقد حددت ر ابطة الطب النفسى الأمريكى (apa, 1987) عـدة معسايير

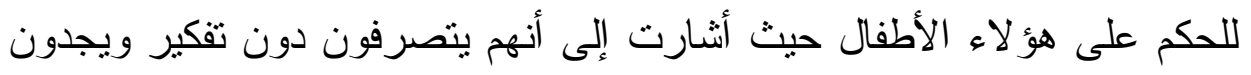
صعوبة فى تتظيم عملهم، وينتقلون بسر عة من عمل إلى أخر قبل إكماله، وكثيراً

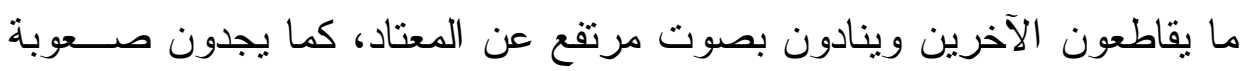
فى إنتظار هم أدو ارهم عند قيامهم بأنشطة معينة. و المشكلة هنا لا تتحصر فى النقص فى معرفة ما يفعلونه، و إنما فى عدم

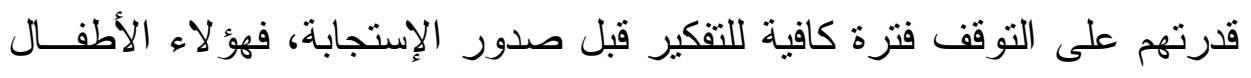

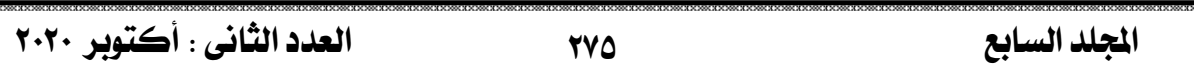


يندفعون بعنف وتهور ، ويكون سلوكهم فى غالبية الأحو ال صـادر اً بدون تفكيـر ،

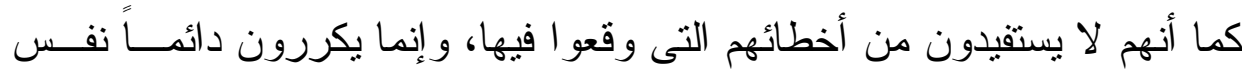
الأخطاء، ولذلك يحتاجون إلى مر اقبةًة أو إثنر اف علــيهم ( Goldstein, et al,

\section{ع. صعوبة الارضاء difficulty With Gratification}

إن الأطفال و المر اهقين من ذوى إضطر اب تشتت الإنتبــاه المــصحوب

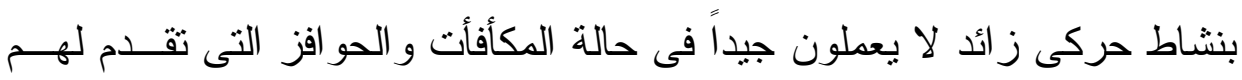

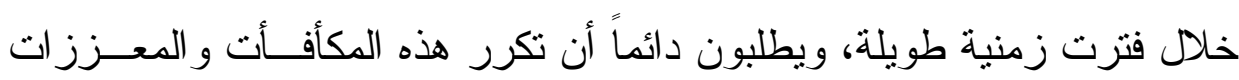
الفورية (Goldstein\&Goldstein, 1995). وقد أثنار بعض الباحثين إلى أن تلك الفئة لا تـستجيب للحـــو افز بــنفس طريقة الأطفال الآخرين، و افترضو أن تكرار حدوث تدعيم سلبى للأطفال ذوى أنى إضطر اب الإنتباه المصحوب بنشاط حركى ز ائد يجعلهم لا يستجيبون للمطالــب إلا عند إز الة المثير المنفر لهم، و هذا عكس ما ينوقعون عنــد حــدوث تــدعيم لاحق(Haenlein\&Caul, 1987, Goldstein, et al, 1995). أسباب إضطر اب تثثت الإنتباه المصحوب بالنشاط الز ائد أتجهت البحوث النفسية و الطبية و التزبويــة لدر اســـة صــبيعة و أســـباب إضطر اب نتنت الإنتباه المصحوب بنشاط حركى، وقدمت تقـسير ات متتو عـــة لتلك الظاهرة، فقد أرجعها البعض إلى عو امل ور اثية، وأرجعها البعض الآخـر

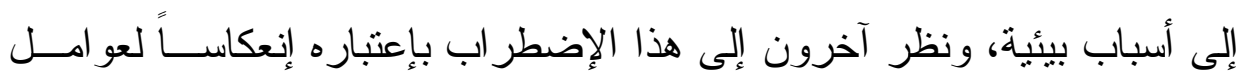
عضوية عصبية، كحدوث خلل وظيفى فى المخً أو حدوث إصابة مخيةً أو نتيجة لعنية 
خلل فى التو ازن الكيميائى أو تأخر فى النضج، وستعرض الباحثة تلك الأسـبـاب فيما يلى:

أولاً: الأسباب الور اثية

ويفترض(Cantwell, 1976:214) أن ظروف نقل الرســائل الور اثيــــة

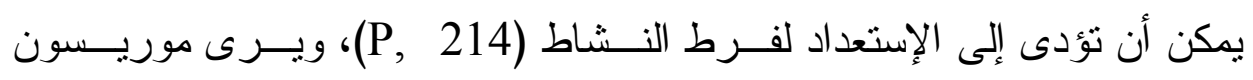

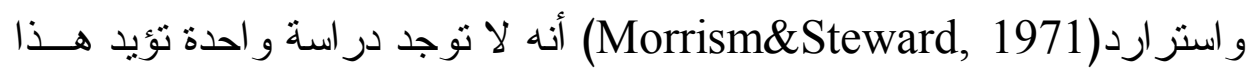

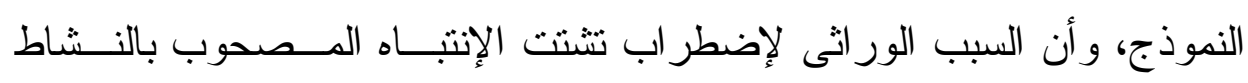

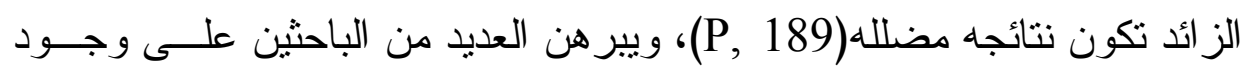

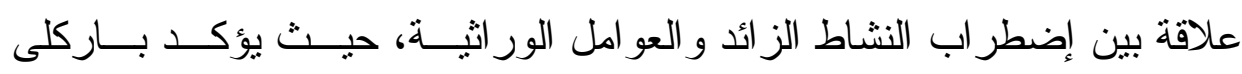
(Barkely, 1985) دور العو امل الور اثئة فى إحداث الإضطر اب، وتوجد دلائل

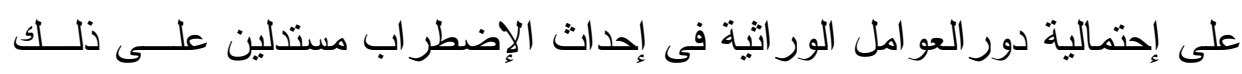

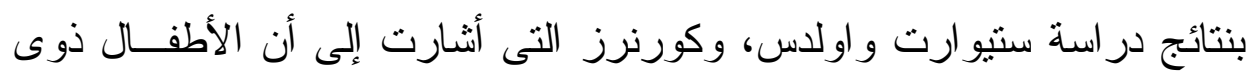

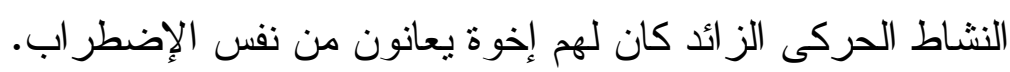

(Stewarts\&Olds, 1973, Corners, et al, 1980)

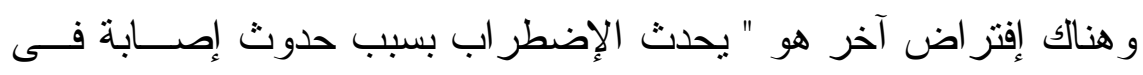

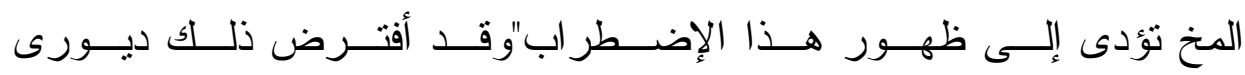

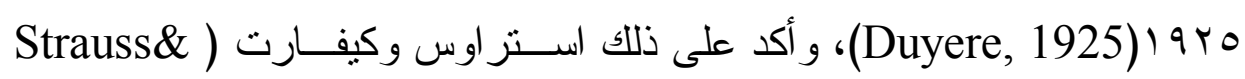

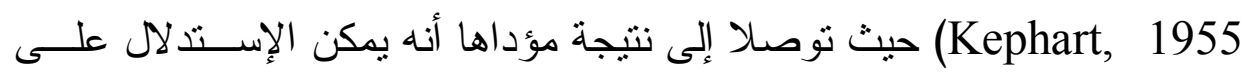

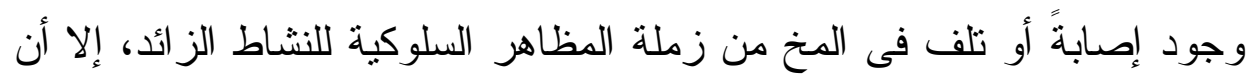
ويرى(Werry) اعترضا على ذللك. 
و أفنترض فلاين و هوبس (Flynn\&Hopson, 1981) أن حسدوث خلــل

وظيفى فى الجهاز العصبى يؤدى إلى ظهور أعر اض هذا الإضطر اب، كمـــا أن

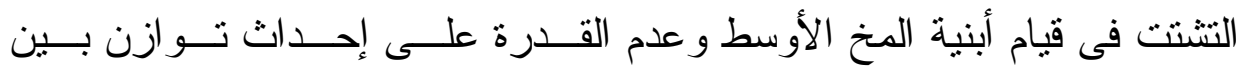
ميكانزمات الكف و الاستثارة يؤدى إلى حدوث هذا الإضطر اب.

ويؤكد باركلى ومعاونوه (Barkely, et al, 1992) أن الخلل الـــوظيفى

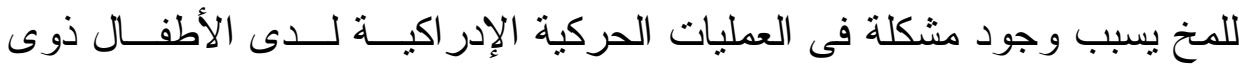
إضطر اب تشتت الإنتباه المصحوب بالنشاط الز ائد. و وناك ر آى آخر يشير إلى أن حدوث خلل فــــ التــوازن البيوكيميــئى ينعكس فى عدم القدرة على إحداث توازن فى الأنظمة الكفية و الإنــتثارية مدــــا يؤدى إلى أعر اض إضطر اب تثتت الإنتباه المصحوب بالنشاط الز ائد. ثانياً: الأسباب البيئية

تعددت العو امل البيئية المسببة لإضطر اب تشتت الإنتبــاه المـصحوب بالنـشاط

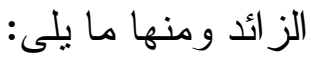

1. التعرض للتسمم بالرصاص نتيجة للأكل و إستخدام بعض اللعب مما يؤدى

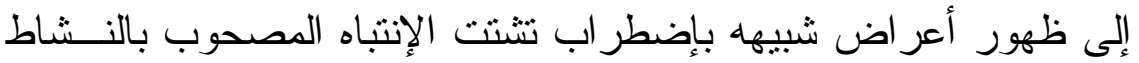

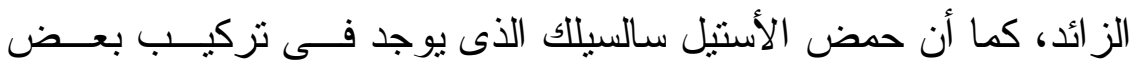

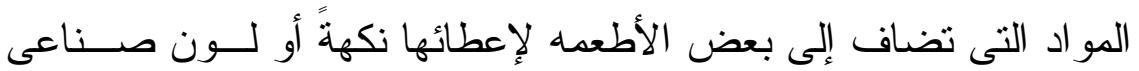
يؤدى إلى حالات مشابهة أيضاً. r. التلوث البيئي خلال فنرة الحمل، أو فترة مر احل الطفولة المبكرة، و التـي يحدث فيها نمو المخ، و الجهاز العصبي. 


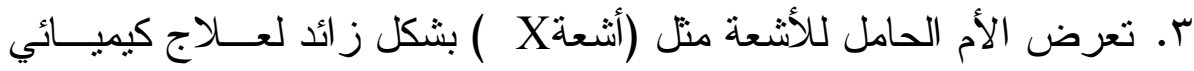

$$
\text { أو إثنعاعي. }
$$

؛. إدمان الأم أثناء الحمل، وتتاول الكحوليات، و التنخين.

ه. إصابة الأم الحامل بأحد العو امل التي توقف تغذية الجنـين بالأكسـين

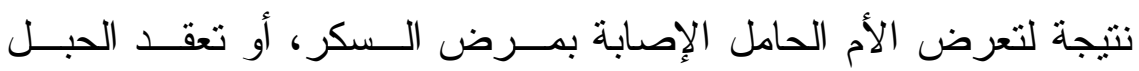

السري، أو الو لادة المتعسرة.

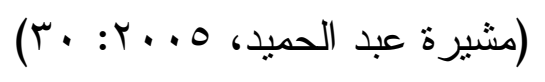

ثالثاً: الأسباب البيئية الاجتماعية

العوامل البيئية المحيطة بالطفل و المتمثلة فى الأسرة و الأساليب الوالديــة

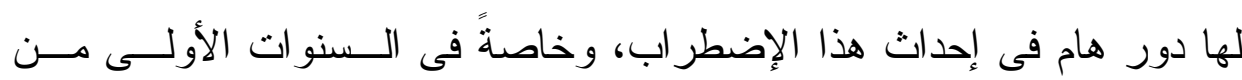

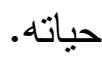

و أكد باركلي Barkley أن إضطر اب تشتت الإنتباه المصحوب بالنـشاط

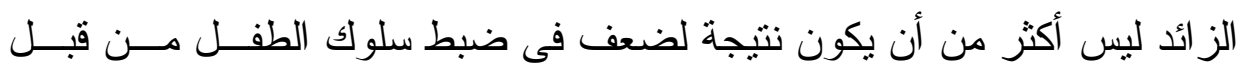
و الديه، إذ أن طرق ترويض سلوك الطفل الضعيفة تؤدى إلى إضطر اب سلوكه. رابعاً: أسباب نفسية

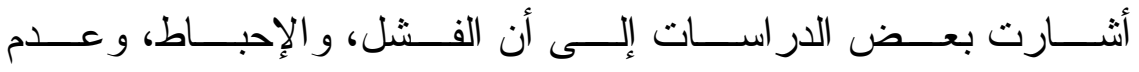

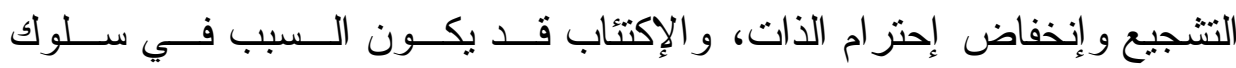

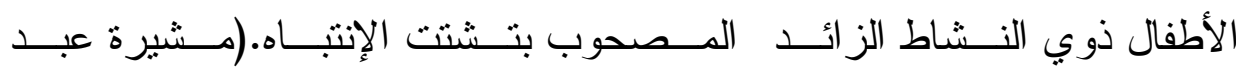

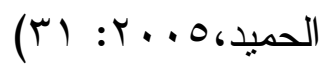


علاج إضطر اب تثتت الإتباه المصحوب بالنشاط الزائد

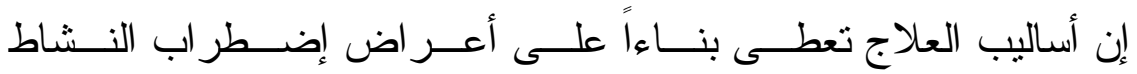

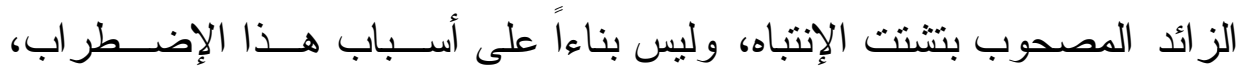

وتتعدد أساليب العلاج، وستعرض الباحثة فيما يلى الأساليب العلاجية المختلفـــة

$$
\text { فيما يلى: }
$$

أولاً: العلاج الطبي Stimulant Medication

من أول الطرق العلاجية التى أستخدمت لخفض ســلـوك تـشتت الإنتبـــاه و النشاط الز ائد العلاج بالعقاقير الطبية المنشطة Stimulants، و أكثـــر العقــــير

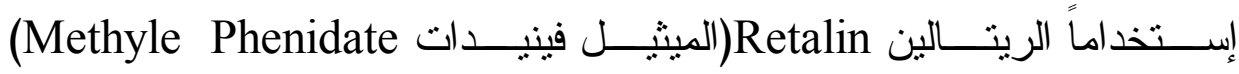

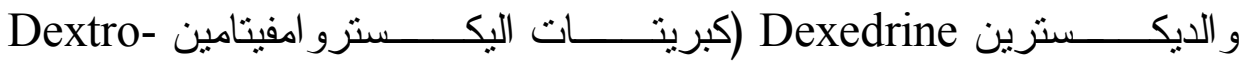
Amphetamine Sulfate .(Safer\&Krager, 1988) Magnesium Pimoline وقد أثنار كـل مــن دوبــال وبــاركلى (Dupaul\&Barkley, 1990)

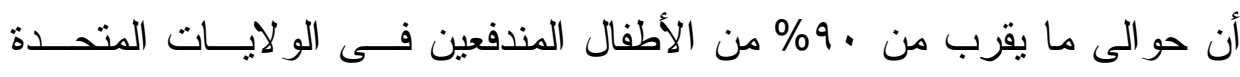

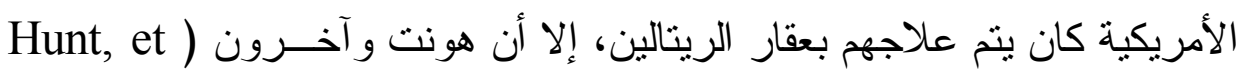
(al, 1991

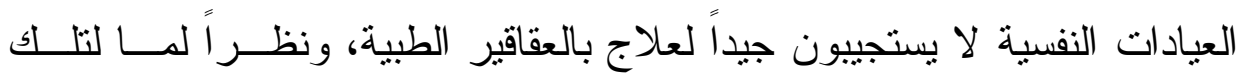
العقاقير من آثار جانبية اتجه غالبية المعالجين إلى التركيز على العلاج السلوكى و العلاج المعرفى. 
ثانياً: التعديل المعرفـي للـسلوك Cognitive Behavior Modification (C.B.M)

يعد التعديل المعرفي من بين أساليب المعالجة المستخدمة مـــع الأطفــال

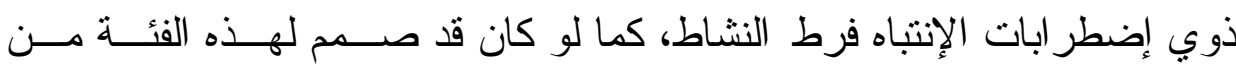
الأطفال بالذات حيث يقوم التعديل المعرفي للسلوك على تدريب هؤلاء الأطفــال

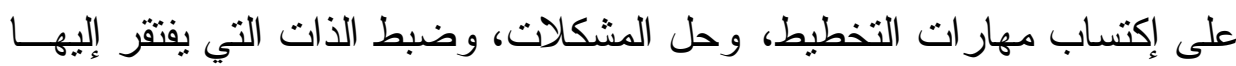

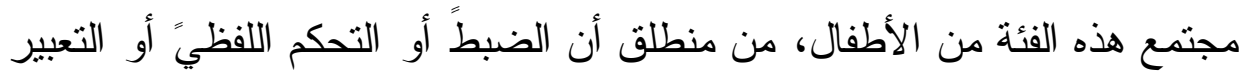

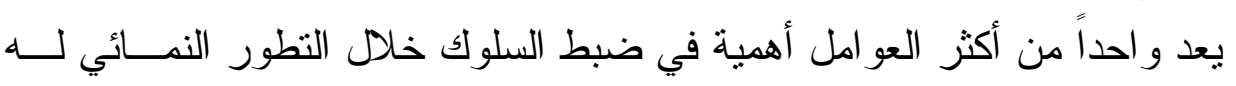

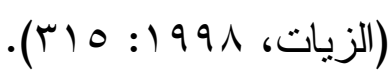

\section{1 ـ تعديل السلوك5 Behavior Modification}

يفضل علماء النفس تعديل السلوك بإستخدام مبادئ التعلم المتكاملـــة عـنـ

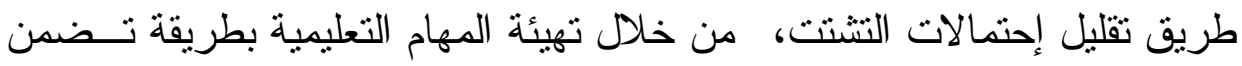

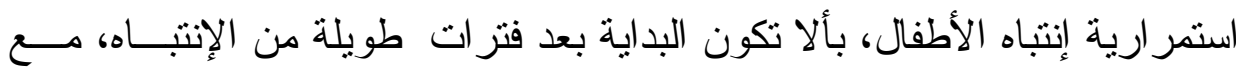

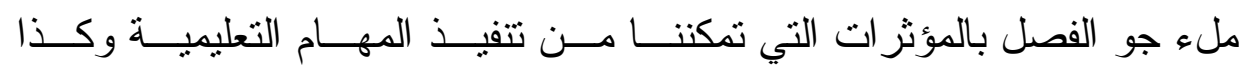

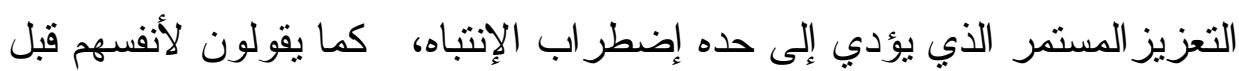

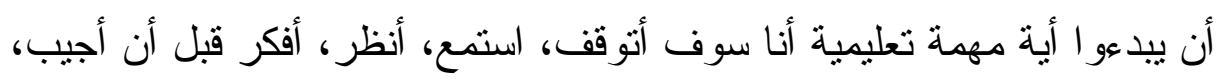

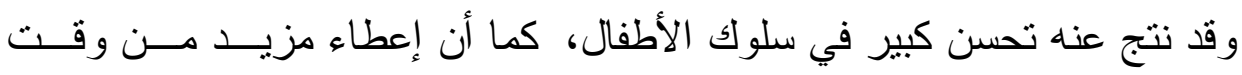

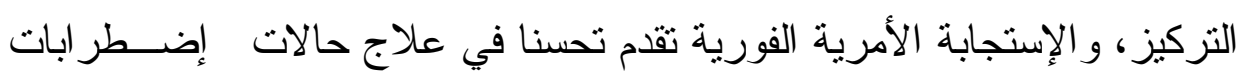

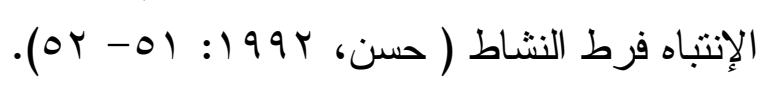

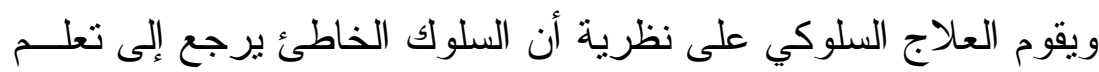

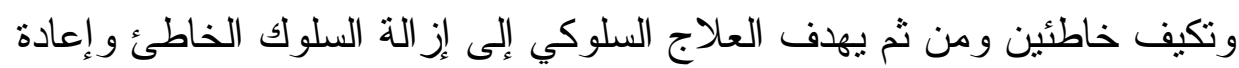

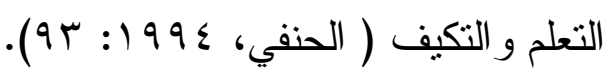

r.r.r. العدد الثانى : أكتوبير

YAI

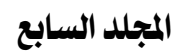


ويقوم التعديل السلوكى على بر امج تعديل السلوك بإتباع طـــرق وفنيــات

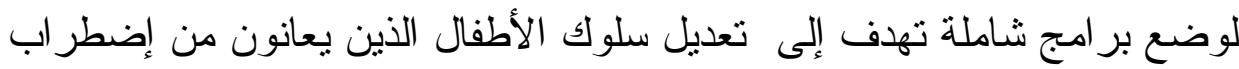

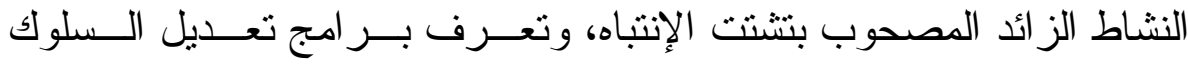
Behavior Modification

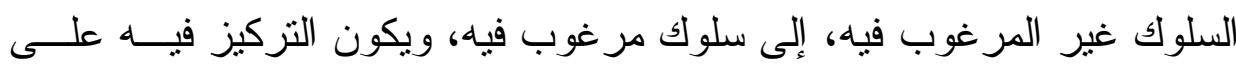

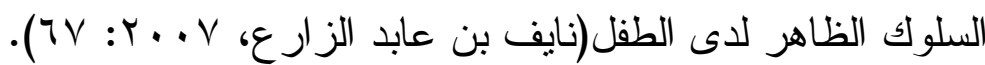
وتستخدم أساليب سلوكية منها أســلوب التعزيــز و اللعــب، و النمذجــة،

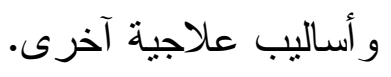

Knowledge Modification تعديل المعرفة

قــام جولدسـتين وجولدسـتين (Goldstein\&Goldstein, 1990)

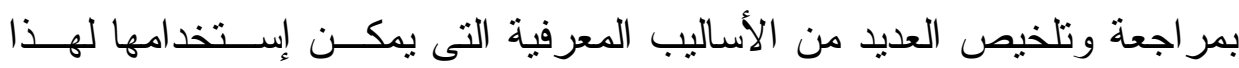
الغرض، وقد تضمنت الأساليب النالية:

هelf-Recording ويقصد بها تعليم الأطفال من خــلد

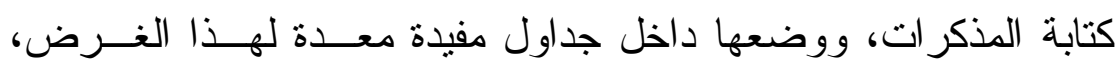
و التقييم الذاتى Self - Evaluation أى تعليم الأطفــال كيفيــة تقيــيم سلوكياتهم بطرق فعالة وصحيحة.

ا التعزيز الذاتى Self - Reinforcement ويقصد بها تعلــيم الأطفــال وتدرييهم على تعزيز ذو اتهم عند قيامه بالأداء الصحيح. ه التعلم الذاتى self-instruction ويقصد بها تعليم الأطفال كيفية التعامل مع المشكلات وكيفية حلها بفاعلية، وتوجية سلوكياتهم بطريقة منظمة. 
ا التدريب القائم على العزو السببى Attribution Training ويقصد بها

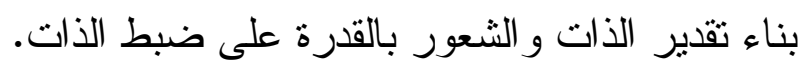

وقد ثبتت فعالية هذه التقنيات فى علاج الأطفال الذين بعانون من تـشتت

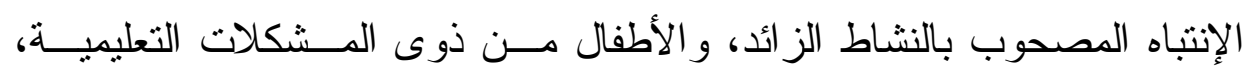

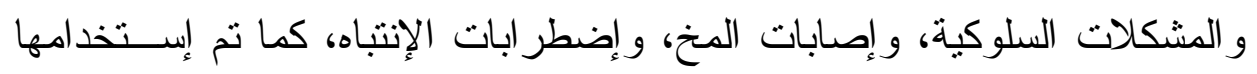

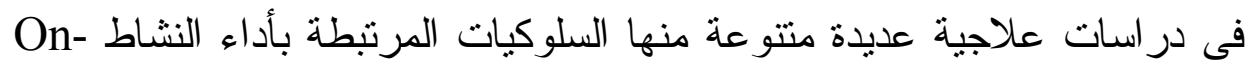
Task Performance و الطاعة، وتقدير الذات، و المهار ات الاجتماعية. إن الإفتر اض المنطقى ور اء إستخدام منل تلأك الأساليب و الفنيات هـــو أن

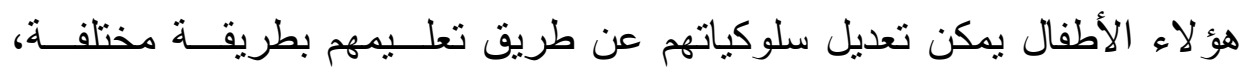

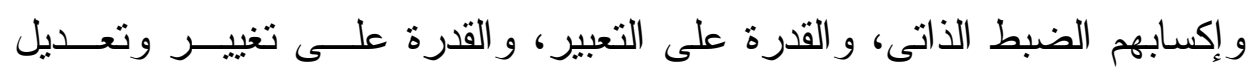
سلوكياتهم بصورة أكثر فعالية. كما يقوم هذا الإتجاه أيضاً على إفتر اض مؤداه أن الإنسان لـــــ سـلبياً

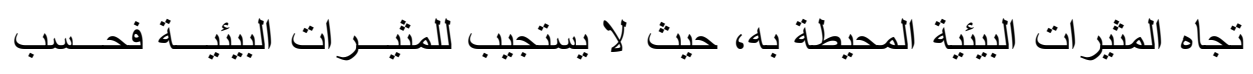

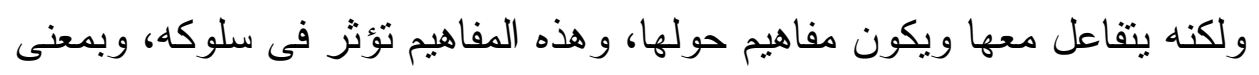

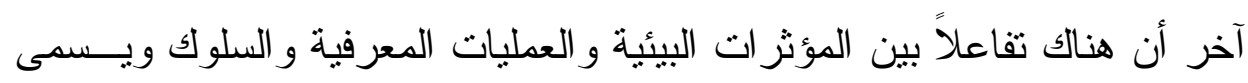
باندورا ( Bandora, 1977 ) هذا التفاعل بالحتمية المتبادلة.

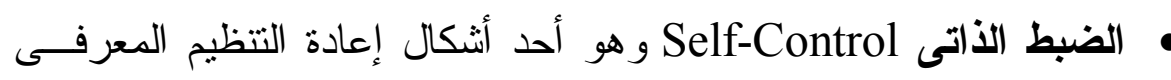

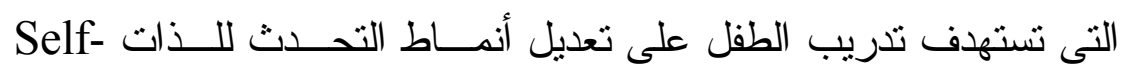

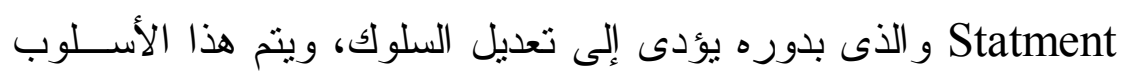

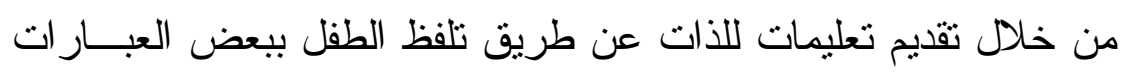

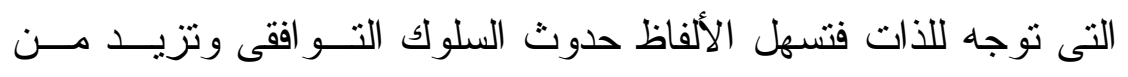


إحتمال حدوثة، وفيه يتعلم الطفل كيف ير اقب نفسه، وكيف يقارن ما بين

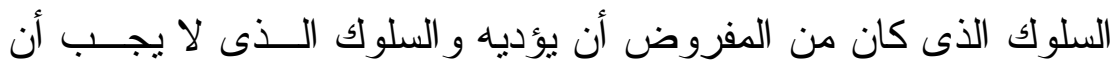

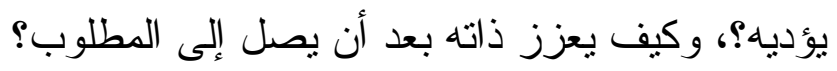

وينصب الاهتمام فى النتظيم الذاتى بإعتباره العنصر الأساسى فى نوجيـــ السلوك و الضبط الذاتى، ويعتبر ميكنبــوم (Michenbaum, 1977) أول مــن فئن طورهذا الأسلوب حيث تبين له أن التخلص من المشكلة يعنـى الــتخلص مــن التحدث إلى الذات بطريقة إنهز امية وسلبية و إستبداله بالتحدث إلى الذات بطريقة

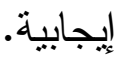

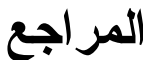

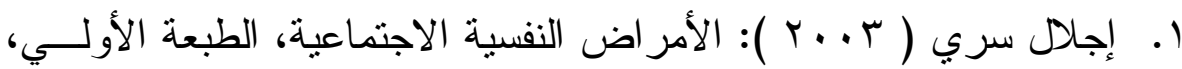

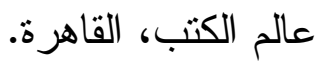

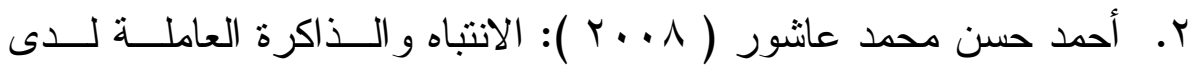

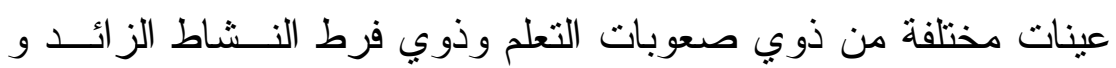
العاديين موقع أطفال الخليج.

r. أحمد عكاثشة(9191(): علم النفس الفـسيولوجى، دار الفكـر العربـى،

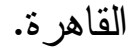

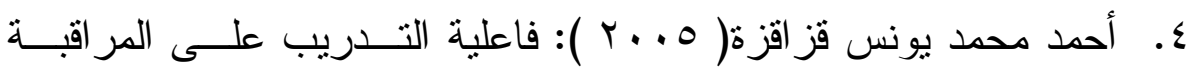
الذاتية في مستوى الانتباه لدى الأطفال الذين لديهم قصور فيـه، موقــع

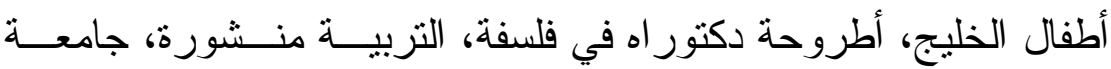

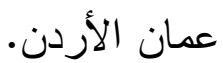


ه. أثرف صبره ( ع 99 ( ) ): در اسة للنشاط الز ائد وقصور الانتبــاه لــدى عينة من طلاب الحلقة الأولى من التعليم الأساســي بمدينــة أســيوط "، رسالة كتور اة غير منشورة، كلية التربية، قسم الأطفال بمحافظات غزة، رسالة ماجستير غير منشورة، كلية التزبية، الجامعة الإسلامية، غــزة، فلسطين.

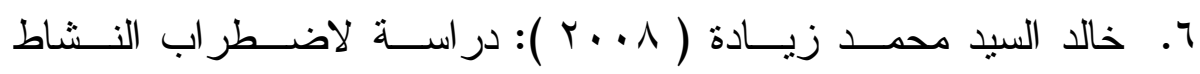

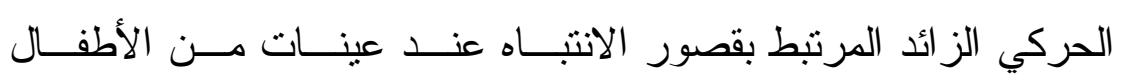

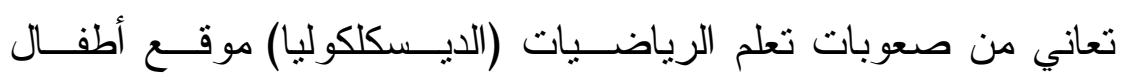
الخليج.

V. رضا أحمد حافظ الأدغم و آخرون ( V. . . ) ): فاعلية استخدام بعـض

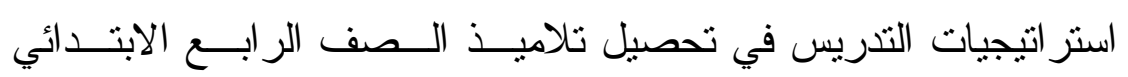
مضطربي الانتباه مفرطي النشاط في اللغة العربية موقع أطفال الخلـيجج العاسمي.

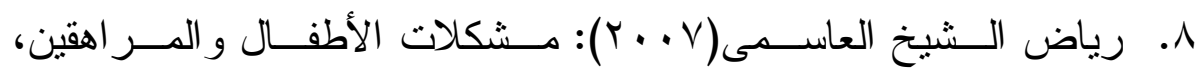
منشور ات جامعة دمثق.

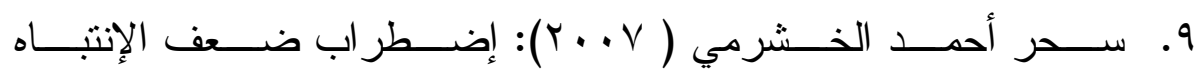

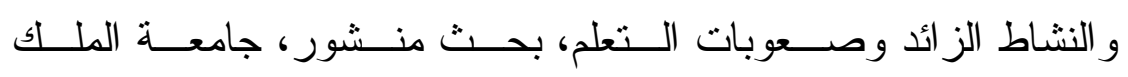
سعود ، السعودية. • 1. السيد إبر اهيم السمادونى( • 99 ( ): الانتبــاه الـسمعى و البــصرى لــدى

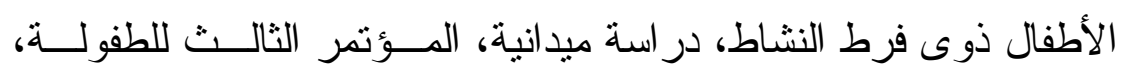

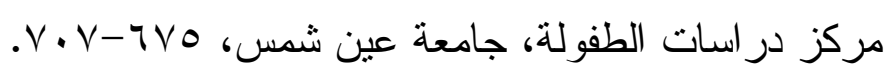

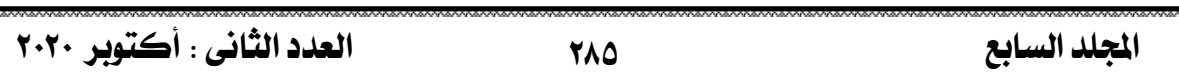




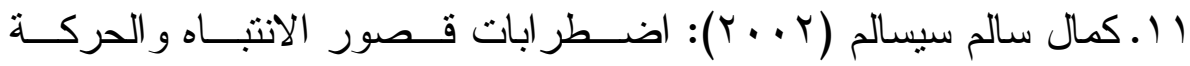

$$
\begin{aligned}
& \text { الدفرطة، دار الكتاب الجامعى، الإمار ات العربية المتحدة. }
\end{aligned}
$$

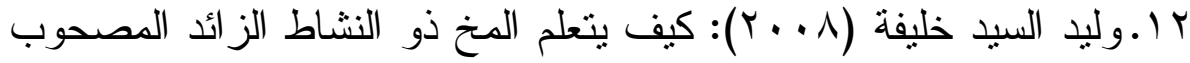

$$
\begin{aligned}
& \text { بتتشت الانتباه، دار و ائل، الأردن. }
\end{aligned}
$$

